\title{
OPEN Temperature dependence of molybdenum dialkyl dithiocarbamate (MoDTC) tribofilms via time-resolved Raman spectroscopy
}

\author{
Carlos E. Garcia, Mao Ueda, Hugh Spikes \& Janet S. S. Wong
}

Molybdenum dialkyl dithiocarbamate (MoDTC) is a friction reducing additive commonly used in lubricants. MoDTC works by forming a low-friction molybdenum disulphide $\left(\mathrm{MoS}_{2}\right)$ film (tribofilm) on rubbed surfaces. MoDTC-induced $\mathrm{MoS}_{2}$ tribofilms have been studied extensively ex-situ; however, there is no consensus on the chemical mechanism of its formation process. By combining Raman spectroscopy with a tribometer, effects of temperature and shear stress on $\mathrm{MoS}_{2}$ tribofilm formation in steel-steel contacts were examined. Time-resolved Raman spectra of the tribofilm were acquired, together with the instantaneous friction coefficient. The tribofilm is constantly being formed and removed mechanically during rubbing. Increasing shear stress promotes $\mathrm{MoS}_{2}$ formation. The nature of the tribofilm is temperature-dependent, with high-temperature tribofilms giving a higher friction than lower temperature films. Below a critical temperature $T_{\mathrm{c}}$ a small amount of $\mathrm{MoS}_{2}$ gives significant friction reduction. Above $T_{c}$ a patchy film with more $\operatorname{MoS}_{2}$, together with a substantial amount of amorphous carbon attributed to base oil degradation, forms. The composition of this tribofilm evolves during rubbing and a temporal correlation is found between carbon signal intensity and friction. Our results highlight the mechanochemical nature of tribofilm formation process and the role of oil degradation in the effectiveness of friction modifier MoDTC.

Around $20 \%$ of the energy consumed every year is lost to friction in mechanical contacts ${ }^{1}$. Reductions in friction translate into significant improvements in energy efficiency, particularly in transport and power generation ${ }^{1}$. Low viscosity oils are increasingly used ${ }^{2,3}$ because they can reduce frictional losses. They are expected to perform under wide ranges of temperature, speed and load. For this reason, a plethora of oil additives is employed in commercial formulations, including friction modifiers, the focus of this study.

Molybdenum dialkyl dithiocarbamate (MoDTC) is a friction modifier lubricant additive widely used alone or in combination with anti-wear additives such as zinc dialkyldithiophosphates (ZDDP). It has been the subject of extensive research since the 1970s. The friction reduction properties of MoDTC are known to be a consequence of the formation of molybdenum disulphide $\left(\mathrm{MoS}_{2}\right)$ flakes at the asperity peaks of rubbing surfaces, with a size of about 10-30 nm in diameter and a thickness of just a few atomic layers. These flakes result in a patchy-albeit effective-surface layer, often called a tribofilm, that can reduce the friction coefficient from typical values of $0.1-0.12$ to as low as $0.05-0.08^{4} . \mathrm{MoS}_{2}$ has a layered structure. Friction anisotropy during interlayer sliding, stemming from $\mathrm{MoS}_{2}$ lattice incommensurability, is shown to be responsible for friction reduction in a $\mathrm{MoS}_{2}$ film ${ }^{5-8}$. Some authors have found correlations between $\mathrm{MoS}_{2}$ surface coverage and macroscopic friction ${ }^{9,10}$. Recent studies have also shown that a constant supply of MoDTC is needed to maintain friction low; if the contact is starved of the additive, the $\mathrm{MoS}_{2}$ film eventually disappears ${ }^{11}$.

The chemical pathways by which MoDTC decomposes upon rubbing and the subsequent formation of $\mathrm{MoS}_{2}$ remain contentious. Several models can be found in the literature. Grossiord et al. introduced a mechanism by which MoDTC breaks up into two free radicals, one of which recombines to form thiuram disulphide and the other one decomposes into molybdenum oxides and $\mathrm{MoS}_{2}$; however, no considerations are made about the role of shear stress in the process ${ }^{12}$. De Barros Bouchet et al. modified this model to explain $\mathrm{MoS}_{2}$ formation in the 


\begin{tabular}{|l|l|l|}
\hline & Ball & Disc \\
\hline Dimensions & $19.05 \mathrm{~mm}$ diameter & $46 \mathrm{~mm}$ disc diameter, $42 \mathrm{~mm}$ track diameter, $5 \mathrm{~mm}$ thickness \\
\hline Materials & AISI 52,100 steel & AISI 52,100 steel \\
\hline Elastic Modulus $(\mathrm{GPa})$ & 207 & 207 \\
\hline Hardness $(\mathrm{Hv})$ & $850 \mathrm{Hv}$ & $835 \mathrm{Hv}$ \\
\hline Poisson ratio & 0.293 & 0.293 \\
\hline Surface Roughness $(\mathrm{nm})$ & $<10 \mathrm{~nm}$ & $<10 \mathrm{~nm}$ \\
\hline
\end{tabular}

Table 1. Dimensions and materials properties of rubbing surfaces.

presence of zinc dithiophosphate (ZDTP), suggesting that ZDTP acts as a net donor of sulfur atoms ${ }^{13}$. Khaemba et al. proposed a two-step mechanism: first, MoDTC on the surface is subject to shear stress and produces $\mathrm{MoO}_{\mathrm{x}}$ and iron oxides. Later, $\mathrm{MoO}_{\mathrm{x}}$ is converted to $\mathrm{MoS}_{2}$ and $\mathrm{FeMoO}_{4}$ is formed from iron oxides ${ }^{14}$. More recently, Kurihara and Phan ${ }^{15}$ presented a five-step mechanism where $\mathrm{MoS}_{2}$ starts forming immediately as a result of the interaction between sulfur atoms in MoDTC and iron. Simultaneously, MoDTC also reacts with FeS, which is produced in the first step, to form more $\mathrm{MoS}_{2}$, together with other products including thiuram disulphide and ferric molybdate $\mathrm{Fe}_{2}\left(\mathrm{MoO}_{4}\right)_{3}$. Since $\mathrm{MoS}_{2}$ formation is enhanced by an intermediate species, this mechanism may collectively be regarded as an autocatalytic reaction, as originally proposed by Graham et al. ${ }^{10}$.

While film formation has been shown to be a tribochemical process, MoDTC tribofilm removal processes have not received much attention in literature. For example, Xu et al. studied the loss of friction reduction capability as a result of additive starvation ${ }^{11}$. However, removal processes could not simply be ascribed to additive starvation conditions because they are a consequence of rubbing and occur continuously.

In this paper, we set out to explore the kinetics of MoDTC tribofilm formation and removal based on $\mathrm{MoS}_{2}$ signal intensity measured by in situ time-resolved Raman spectroscopy, which we correlate to macroscopic friction ${ }^{16,17}$. By examining the formation of $\mathrm{MoS}_{2}$ in real time, we investigate:

1. How test temperature affects the effectiveness of MoDTC friction modifier

2. How test temperature affects the formation and nature of the $\mathrm{MoS}_{2}$ tribofilm

\section{Methods}

Tribometer. Tribological tests were performed using an MTM2 ball-on-disc tribometer from PCS Instruments. In this device, a ball and the flat surface of a disc are pressed against each other to form a contact. The ball and the disc are rotated by independent motors, allowing different disc and ball surface speeds $\left(U_{b}\right.$ and $U_{d}$ respectively) at the contact to be established. A cantilever loading system applies the required force on the shaft pushing the ball against the disc, while the resulting frictional force is measured by a load cell attached laterally to the shaft at an acquisition rate of $1 \mathrm{~Hz}$. During a friction test, a circular contact track is formed on the disc. The friction coefficient is calculated and its variation with time is recorded to produce a friction curve. Friction curves shown in this work are the result of applying a FFT smoothing filter to the friction signal with a cutoff frequency of $0.33 \mathrm{~Hz}$, hence supressing high-frequency fluctuations.

All specimens (see Table 1) were sourced from PCS and were from the same manufactured batch. They were cleaned prior to test by submerging in a toluene ultrasonic bath for $30 \mathrm{~min}$, followed by a further ultrasonic bath in acetone. Any remaining residue was removed using a hexane-soaked lint free wipe. The specimen was then submerged without delay in the testing oil blend to minimise oxidation or contamination of the surface.

Raman spectroscopy. The surface of the disc was examined by Raman spectroscopy. A monochromatic laser beam is focussed on a small spot on the sample surface and the scattered light is collected. The elastic component of the scattered light is optically filtered out and the inelastically scattered light is analysed in a spectrometer. The spectral signature of a substance is determined by the transitions between molecular vibrational states. The Raman spectrum of the MoDTC additive is complex due to its many vibrational modes possible. In the case of $\mathrm{MoS}_{2}$, however, there are two Raman-active transitions corresponding to the in-plane and out-ofplane vibrations of the molecule, $\mathrm{E}_{2 \mathrm{~g}}{ }^{1}$ and $\mathrm{A}_{1 \mathrm{~g}}$, that result in strong spectral peaks near 380 and $410 \mathrm{~cm}^{-1}$. Other species potentially relevant to the chemistry of this system also possess distinct Raman spectral peaks, including $\mathrm{MoO}_{3}\left(820\right.$ and $\left.994 \mathrm{~cm}^{-1}\right)$ and $\mathrm{Fe}_{2} \mathrm{O}_{3}\left(615 \mathrm{~cm}^{-1}\right)$. Should the base oil used in this study undergo degradation and form amorphous carbon, peaks near 1350 and $1580 \mathrm{~cm}^{-1}$, commonly known as the D- and G- bands, may also be observed ${ }^{18}$. Reference spectra are provided in SI 1 of the Supplementary Information file.

Experimental apparatus. A custom-built Raman micro-spectrometer was fitted to the tribometer in an epi-illumination configuration, using a $488 \mathrm{~nm}$ CW laser (Spectra-Physics Cyan $100 \mathrm{~mW}$ ), an Andor Shamrock SR-500i spectrometer with an iDus 401 CCD camera, a Falcon EM-CCD camera from Raptor Photonics and a $20 \times$ Olympus microscope objective with NA 0.5, as shown in Fig. 1. The objective approached the surface of the disc vertically, focussing the laser beam on the disc. The laser spot size on the disc was approximately $2 \mu \mathrm{m}$. The tribometer was mounted on a 2 -axis translatable platform. The position of the tribometer relative to the laser spot was adjusted using micrometric screws. Two additional light sources were built into the apparatus: a visible LED that permitted micrographs of the surface to be taken and a Neon lamp for spectral calibration. 


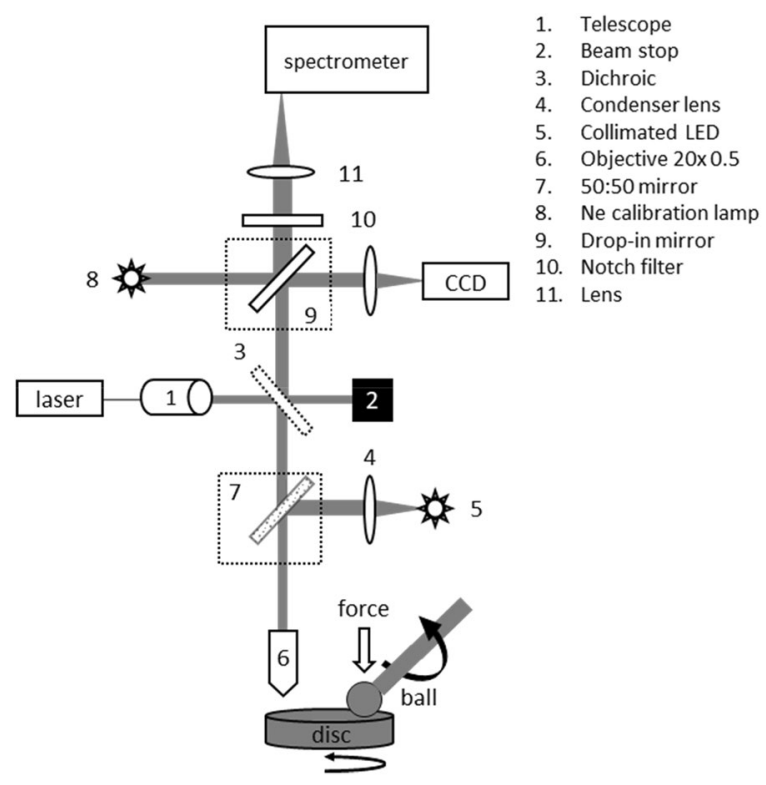

Figure 1. Schematic of the in-situ Raman apparatus.

\begin{tabular}{|l|l|l|l|l|l|l|l|l|}
\hline $\mathbf{T}\left({ }^{\circ} \mathbf{C}\right)$ & Ball speed $(\mathbf{m m} / \mathbf{s})$ & Disc speed $(\mathbf{m m} / \mathbf{s})$ & $\begin{array}{l}\text { Entrainment speed } \\
(\mathbf{m m} / \mathbf{s})\end{array}$ & Force $(\mathbf{N})$ & MoDTC wt\% $(\mathbf{p p m})$ & Test duration (min) & Exposure time $(\mathbf{s})$ & Raman location \\
\hline $60-110$ & 5 & 35 & 20 & $30-70$ & $0-500$ & 60 & 10 \\
\hline
\end{tabular}

Table 2. Range investigated for each experimental test condition.

Raman measurements were obtained during rubbing at a location situated 90 degrees upstream of the contact on the disc surface. The friction curve was recorded simultaneously. The Raman signal was collected with an exposure time of $10 \mathrm{~s}$ on a continuous cycle and read out immediately $(34 \mathrm{~ms})$. The disc undergoes approximately two rotations during each exposure. Hence the resulting spectrum is averaged along the contact track. Raman spectra were collected both at the centre and at the edge of the contact track.

To minimise the amount of oil on the surface at the point of measurement, an air jet was delivered through a $750 \mu \mathrm{m}$ diameter nozzle to locally push oil away, momentarily exposing the surface as the disc turns. The disc surface becomes fully flooded with oil again before the next pass of the ball occurs. The use of air jet does not affect the formation of the tribofilm (see SI 2 for more information).

Test conditions. The lubricant contained $1.11 \mathrm{~g}$ of a commercial form of MoDTC (Adeka Sakura 165) for every $98.89 \mathrm{~g}$ of PAO base oil (Durasyn 164), resulting in a molybdenum concentration of $0.05 \%$ wt. To ensure the mixture was well dispersed, it was subjected to a 30-min ultrasonic bath at room temperature prior to each experiment. Unless otherwise stated, tests were performed at a disc and ball speeds of $35 \mathrm{~mm} / \mathrm{s}$ and $5 \mathrm{~mm} / \mathrm{s}$ respectively (i.e. entrainment speed of $20 \mathrm{~mm} / \mathrm{s}$, a sliding speed of $30 \mathrm{~mm} / \mathrm{s}$ ), and a load of $70 \mathrm{~N}$. This results in a maximum Hertzian contact pressure of $1.24 \mathrm{GPa}$ and a Hertzian contact diameter of approximately $320 \mu \mathrm{m}$. Temperature was varied between $60^{\circ} \mathrm{C}$ and $110^{\circ} \mathrm{C}$. Based on the test conditions and the properties of the fluid, a Couette-flow EHL calculation ${ }^{19}$ estimated the lubricant film thickness in the contact at $1.7 \mathrm{~nm}$. This is smaller than the surface roughness of contact surfaces. These conditions were chosen so that direct contact between the two rubbing surfaces was expected, a condition that favours $\mathrm{MoS}_{2}$ tribofilm formation. All tests had a duration of $1 \mathrm{~h}$. Where MoDTC had been added to the oil, an $\mathrm{MoS}_{2}$ tribofilm formed slowly, as evidenced by the rise of $\mathrm{MoS}_{2}$ Raman peaks in the collected spectra over time (see Supplementary Information SI 3). A summary of the test conditions is shown in Table 2.

Data analysis. Raman spectra were imported into MATLAB for further processing. A baseline fit was calculated and subtracted from each spectrum. Then, the temporal evolution of the $\mathrm{A}_{1 \mathrm{~g}}$ peak intensity, $I_{\mathrm{Mos}_{2}}$, was computed (schematically shown in blue lines, Fig. 2) and reported with their corresponding friction curves (schematically shown in red lines, Fig. 2).

Depending on test temperature, two types of behaviour were observed. Type A cases occur in tests conducted below $90^{\circ} \mathrm{C}$, where the friction coefficient drops while $I_{\mathrm{Mos}_{2}}$ rises initially before they both plateau (Fig. 2a). In these cases, the initial rate of increase in $I_{\mathrm{Mos}_{2}}, r_{\mathrm{Mo}-i}$ was determined from the initial slope of the asymptote fit to 


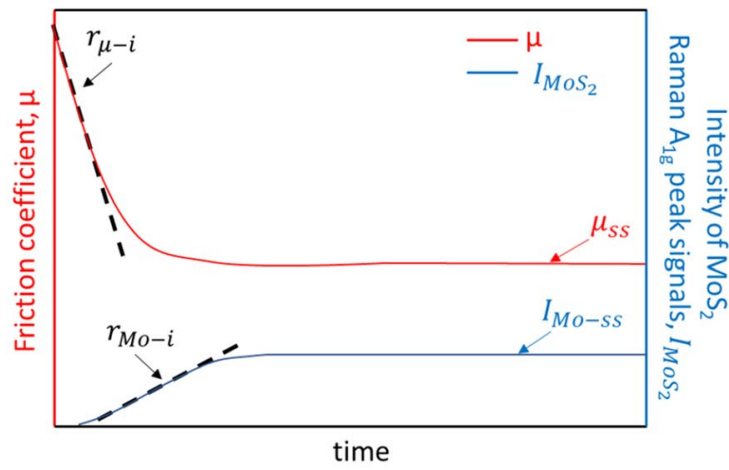

(a) Temperature $<90^{\circ} \mathrm{C}$ : Type A behaviour

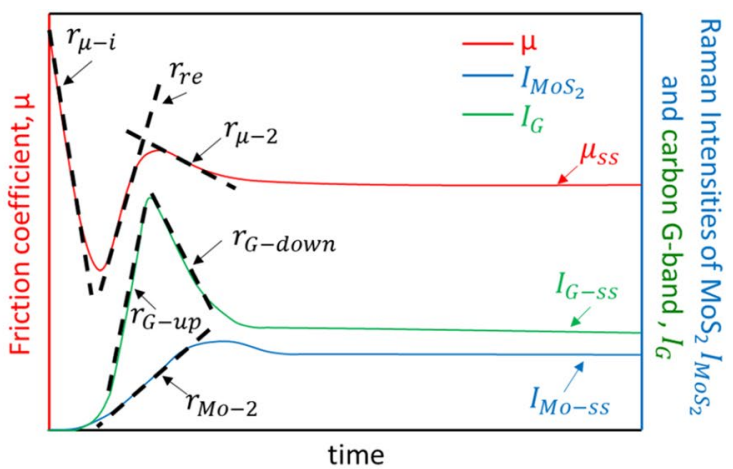

(b) Temperature $\geq 90^{\circ} \mathrm{C}$ : Type $\mathrm{B}$ behaviour

Figure 2. Typical friction curves and time-resolved $\mathrm{MoS}_{2}$ and carbon Raman signals indicating how the different rates are defined for test performed at: (a) $\mathrm{T}<90^{\circ} \mathrm{C}$-type A case; and (b) $\mathrm{T} \geq 90{ }^{\circ} \mathrm{C}-$ - type $\mathrm{B}$.

the data (blue line, Fig. 2a). Similarly, the initial rate of decrease of the friction coefficient $r_{\mu-i}$ was determined from a linear fit of the initial straight portion of the friction curve (red line, Fig. 2a).

Type $\mathrm{B}$ cases occur when test temperature $\geq 90^{\circ} \mathrm{C}$. In these cases, the friction coefficient rises again after its initial reduction. It then reaches a local maximum before it drops and plateaus (see red line, Fig. $2 \mathrm{~b}$ ). In these cases, two other rates are defined (see red line, Fig. 2b): the rebound rate $r_{r e}$ is defined as the average rate of increase of friction coefficient between the local minimum and local maximum of the friction curve; and the second rate of decrease of friction coefficient, $r_{\mu-2}$, is the average rate of change of friction between the local maximum friction and the steady state friction. When the friction curve exhibits Type B behaviour, a sharp increase in $\mathrm{IMos}_{2}$ occurs after the minimum friction coefficient is reached. Hence no $r_{M o-i}$ is estimated, instead $r_{M o-2}$ as shown in Fig. $2 \mathrm{~b}$ (blue line) is used.

In cases where carbon D-band and G-band are observed in Raman spectra, their intensities, $I_{D}$ and $I_{G}$ respectively, were monitored. For type A cases, $r_{D-i}$ and $r_{G-i}$ are defined in the same way as $r_{M o-i}$. For type B cases, their $I_{D}$ and $I_{G}$ curves show a rise, follows by a drop before reaching a plateau (see green line, Fig. $2 \mathrm{~b}$ ). Their rates of change of intensity, $r_{D-u p}$ and $r_{G-u p}$, are defined in the same way as $r_{r e}$; and $r_{D-\text { down }}$ and $r_{G-\text { down }}$ the same way as $r_{\mu-2}$.

All rates are presented as their absolute value (always positive). Friction coefficient, $I_{\mathrm{MoS}_{2}}$, and in cases where carbon D- and G- bands are observed, $I_{D}$ and $I_{G}$, eventually reach steady state values of $\mu_{s s}, I_{M o-s s}, I_{D-s s}$ and $I_{G-s s}$ respectively. Wherever a single steady state value is provided for friction and Raman signals, it is computed by averaging the steady-state portion of the curve and discarding the initial transients. Since each experimental condition was repeated several times, the error bar represents the standard deviation of the individual measurements.

To distinguish Raman intensities and growth rates taken from spectra obtained at the edge of the contact track from those obtained at the centre of the track, ()$_{-e}$ are rates and intensities related to edges of tracks.

Ex-situ surface characterisation. Ex-situ surface characterisation was carried out on contact tracks of steel discs obtained at $60^{\circ} \mathrm{C}$ and $110^{\circ} \mathrm{C}$. AFM profiles of contact tracks were acquired using a WiTec alpha300RA with a V-shaped silicon nitride cantilever in contact mode. SEM scans of the surface were obtained using a HITACHI S-3400 N in secondary electrons mode; also, an Oxford Instruments INCA EDX detector was used to measure elemental composition. XPS data was obtained with a ThermoFischer H-Alpha spectrophotometer using a monochromatic Al- $\mathrm{K}_{\alpha} \mathrm{X}$-ray source $(1486.6 \mathrm{eV})$ with $200 \mu \mathrm{m}$ spot size.

\section{Results}

Rubbing causes the formation of $\mathrm{MoS}_{2}$. The two Raman peaks of $\mathrm{MoS}_{2}, \mathrm{E}_{2 \mathrm{~g}}{ }^{1}$ and $\mathrm{A}_{1 \mathrm{~g}}$, are detected on contact tracks. In some cases, strong signals from the D $\left(1350 \mathrm{~cm}^{-1}\right)$ and $\mathrm{G}\left(1580 \mathrm{~cm}^{-1}\right)$ bands associated with amorphous carbon also appear (see supplementary information SI 4). A typical $\mathrm{IMos}_{2}$ profile across the contact track obtained after a friction experiment is shown in Fig. 3. $\mathrm{IMos}_{2}$ at each location is an average of four measurements. $\mathrm{MoS}_{2}$ is present at the contact, with a local maximum at the centre of the track observed in some cases. Strong $\mathrm{MoS}_{2}$ signals are also detected just outside of the track. This is confined to a region less than one contact diameter $(\sim 340 \mu \mathrm{m})$ from the track. No $\mathrm{MoS}_{2}$ is detected on other regions of the disc surface. The general features of the profiles shown in Fig. 3 are observed in all tests, regardless of whether an air jet was used during the test (see Supplementary Information SI 3).

Chemical composition of tribofilms based on ex-situ analysis. Optical microscopy shows small black patches scattered on the contact tracks (see Fig. S6-1 in SI 6). The amount and size of black patches increase with increasing test temperature. The morphology and the composition of the tribofilms formed at low and high temperatures differ. AFM images of the contact track show a $10-20 \mathrm{~nm}$ thick tribofilm after a $60{ }^{\circ} \mathrm{C}$ rubbing test (see Fig. S7-2b in SI 7). EDX confirms this thin film contains Mo and S (Fig. 4a). Note that Mo and S are negligible outside the contact track. Thicker patches (>100 nm, see Fig. S7-1 in SI 7) are found after a $110{ }^{\circ} \mathrm{C}$ test. EDX analysis indicates these patches have relatively high Mo and C content (see Fig. 4b). XPS analysis of 


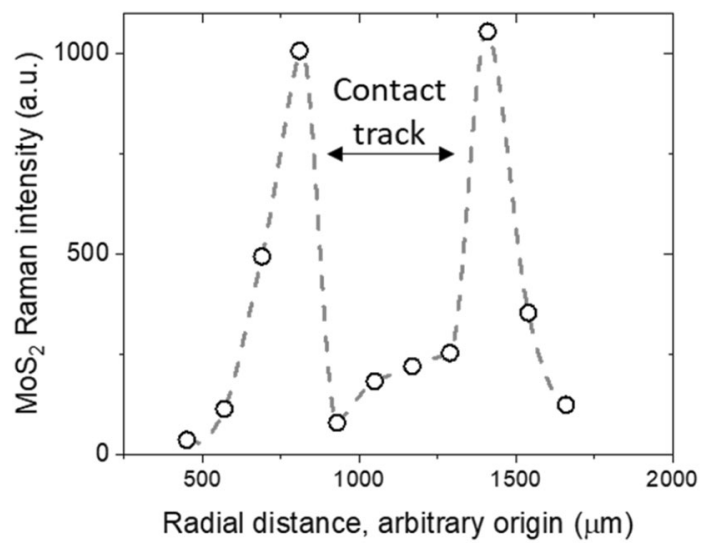

Figure 3. Typical radial $\mathrm{MoS}_{2}$ intensity profile across a contact track measured after the test.

(a) $60^{\circ} \mathrm{C}$

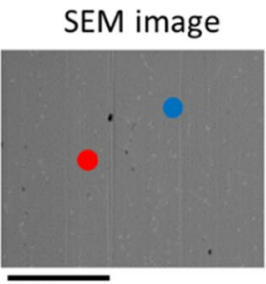

$\overline{100 \mu \mathrm{m}}$

(b) $100^{\circ} \mathrm{C}$

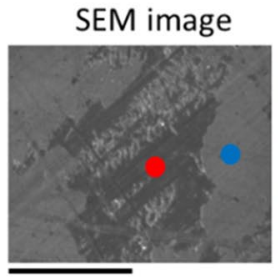

$60 \mu \mathrm{m}$
Mo
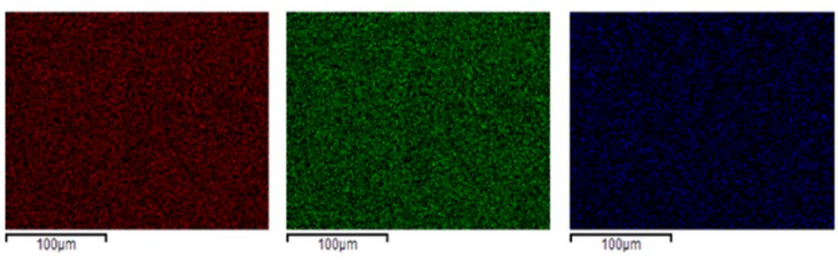

$100 \mathrm{vm}$

C
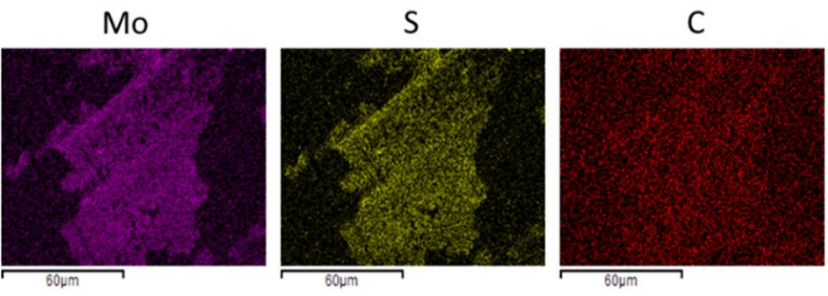

Atomic composition (\%)

\begin{tabular}{|c|c|c|}
\hline & $\bullet$ & 2 \\
\hline $\mathrm{Fe}$ & 61.4 & 83.0 \\
\hline $\mathrm{C}$ & 25.9 & 10.7 \\
\hline $\mathrm{Mo}$ & 3.0 & 0.2 \\
\hline $\mathrm{S}$ & 2.3 & 0.1 \\
\hline
\end{tabular}

Figure 4. SEM image and EDX scan of contact tracks without wiping showing relative chemical abundance of molybdenum, sulphur and carbon after a test at (a) $60{ }^{\circ} \mathrm{C}$ and (b) $110^{\circ} \mathrm{C}$.

contact tracks suggest that these patches contain higher fraction of $\mathrm{Mo}^{4+}$ than the low temperature tribofilm (see SI 9). These patches can be easily removed with a gentle wipe, after which a 10-20 nm film (Fig. S7-2a in SI 7) of similar Mo and C contents to those of the low-temperature film remains (Fig. S8-1 in SI 8). This implies that the patches adhere weakly to rubbing surfaces. Our results suggest that the high-temperature film is likely to be composed of at least two layers: (1) a top, patchy layer (approximately $100 \mathrm{~nm}$ thick), contains relatively high Mo and $\mathrm{C}$ contents; and (2) a bottom layer (about tens of $\mathrm{nm}$ ), with lower $\mathrm{C}$ and Mo content, similar to that formed at lower temperature.

Linking friction reduction to nature of tribofilm. Tests conducted at temperatures below $90{ }^{\circ} \mathrm{C}$ exhibit Type A behaviour; the friction coefficient gradually reduces until a steady state is reached (red line, Fig. 5a). At the centre of the contact, an increase of $I_{M_{0 s}}$ (blue triangles, Fig. 5a) is observed during the test. $I_{M_{o s}}$ continues to rise slightly after the friction coefficient stabilises (see inset in Fig. 5a). Note that $I_{D}$ and $I_{G}$ (green circles and black squares, Fig. 5a) are relatively constant throughout the test.

Tests conducted at $100^{\circ} \mathrm{C}$ and $110^{\circ} \mathrm{C}$ show type B behaviour (Fig. 5b); a 'bump' is seen in the friction curve after the minimum friction is reached (red, Fig. 5b). This also occurs, although less obviously, in some tests conducted at $90{ }^{\circ} \mathrm{C}$. In these high temperature cases, $I_{\mathrm{Mos}_{2}}$ (blue triangles), $I_{D}$ (green circles) and $I_{G}$ (black squares) in the contact track, together with the friction coefficient (red line), rise substantially after friction has reached its minimum. At this rising phase, $I_{D}$ and $I_{G}$ are higher than $I_{M o s_{2}} . I_{D}, I_{G}$ and the friction coefficient follow a similar trend: all reach maximum at roughly the same time, before they all decrease and then plateau. On the other hand, $I_{\mathrm{Mos}_{2}}$ reaches a maximum and then stabilises. 

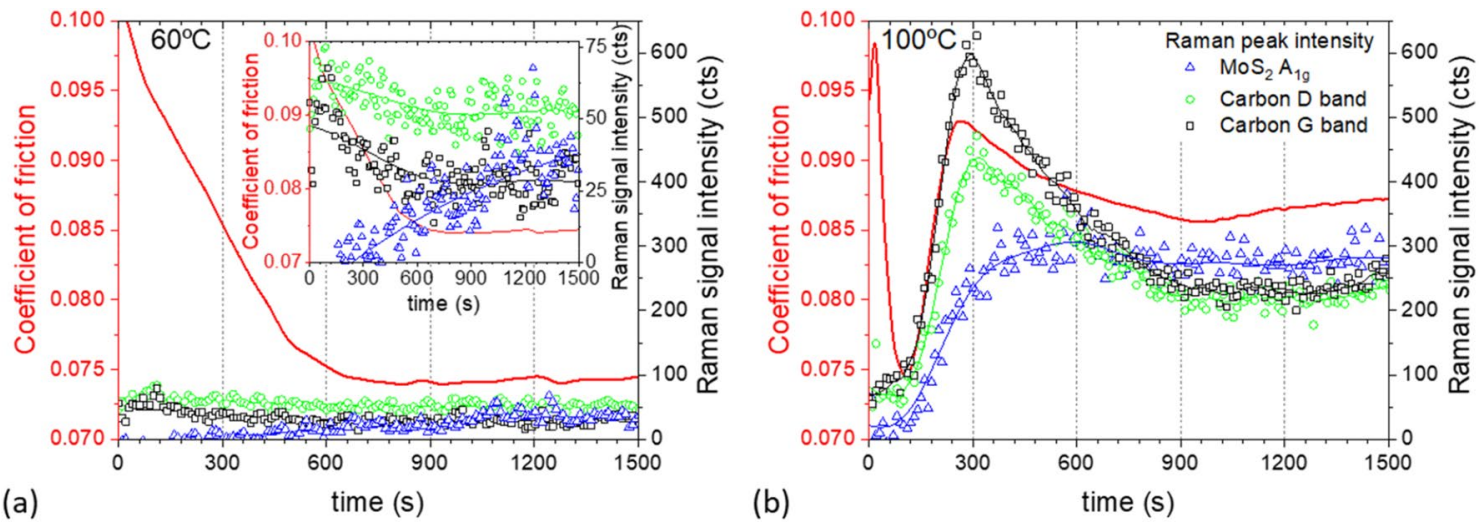

Figure 5. Friction curves and Raman signals measured at the centre of the contact track at (a) $60{ }^{\circ} \mathrm{C}$; and (b) $100{ }^{\circ} \mathrm{C}$. Data obtained at an applied load of $70 \mathrm{~N}$, disc speed $=35 \mathrm{~mm} / \mathrm{s}$ and ball speed $=5 \mathrm{~mm} / \mathrm{s}$.
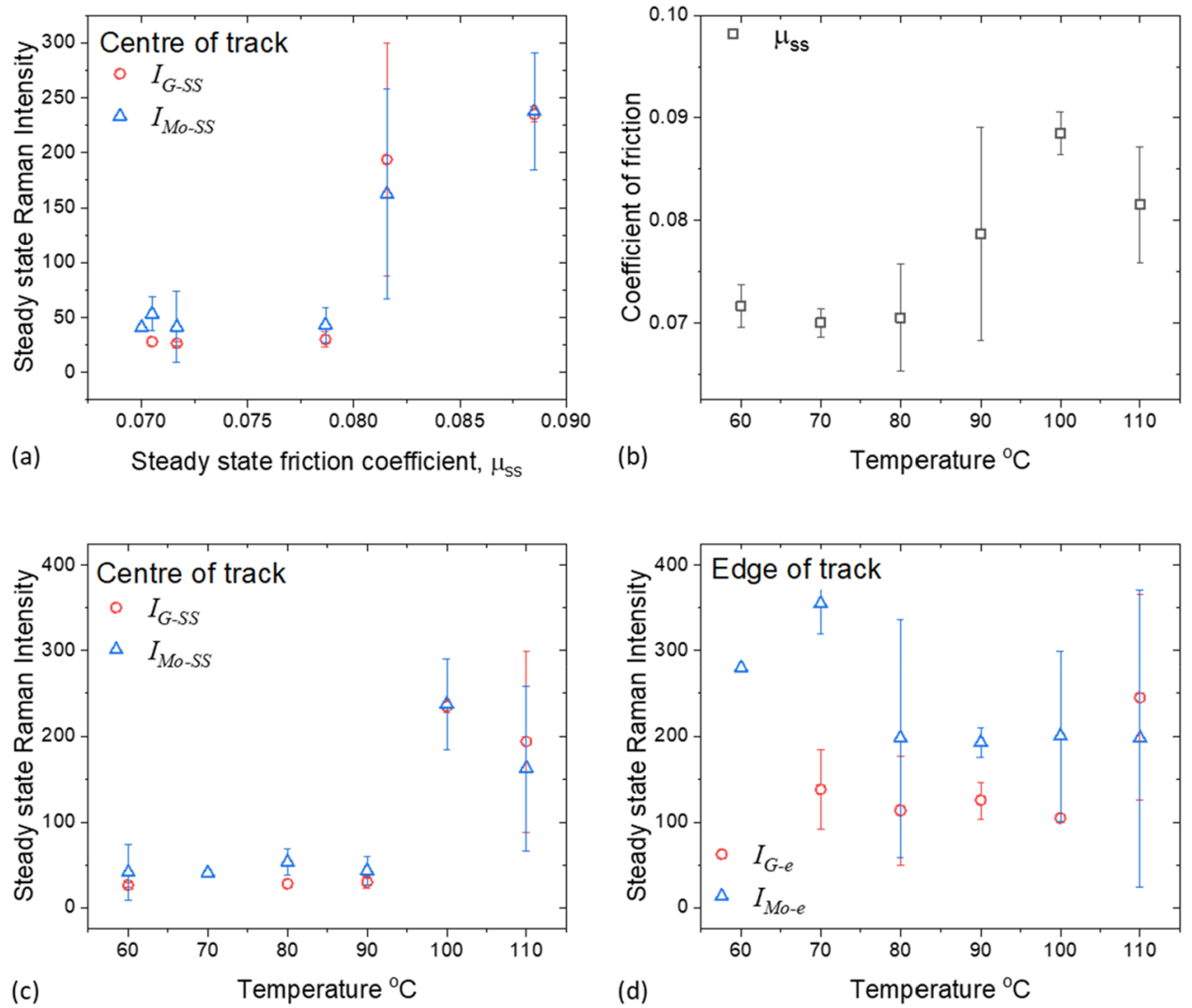

Figure 6. (a) The relationship between steady-state Raman intensities of $\mathrm{MoS}_{2}$, G-band obtained at the contact track, and steady state friction coefficient, temperature: $60-110^{\circ} \mathrm{C}$ and Load $=70 \mathrm{~N}$; the effect of test temperature on (b) friction coefficients; (c) steady state Raman intensities of $\mathrm{MoS}_{2}$, and G-band obtained in the contact track; (d) steady state Raman intensities of $\mathrm{MoS}_{2}$, and G-band obtained at the edge of the contact track. Note the Raman intensity of D-band is similar to that of G-band in all cases and is omitted for clarity.

The effect of temperature on the steady state friction coefficient and the steady state Raman intensities of $\mathrm{MoS}_{2}$, and G-band of carbon obtained in the track are presented in Fig. 6b,c respectively. Note that the Raman intensities of D-band are similar to those of G-band in all cases and are omitted for clarity. At a fixed temperature, $I_{M o-s s}$ (triangles) and $I_{G-s s}$ (circles) are similar (see Fig. 6c). $I_{M o-s s}$ obtained at temperatures between 60 and $90{ }^{\circ} \mathrm{C}$ have similarly low values, while those from 100 and $110^{\circ} \mathrm{C}$ tests are higher. The same is true for $I_{D-s s}$ and $I_{G-s s}$. This indicates that a transition temperature exists around $90^{\circ} \mathrm{C}$. Such temperature transition is also observed with friction coefficient (Fig. 6b): $\mu_{s s}$ is low when test temperature $<90^{\circ} \mathrm{C}$, above which it increases. Our results show that the performance of MoDTC can broadly be divided into two types: low $I_{M o-s s}$, which 

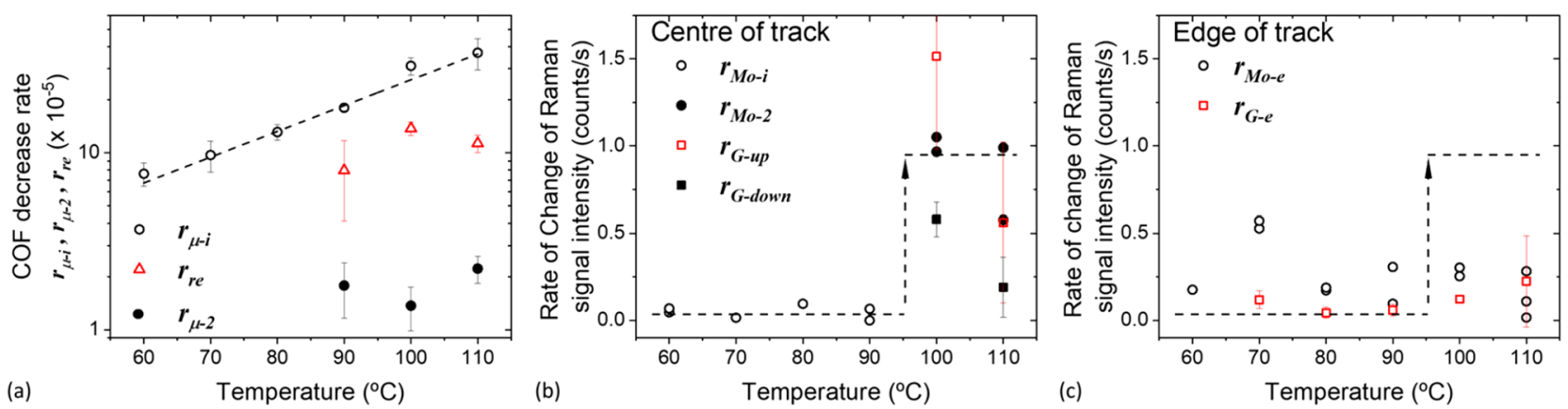

Figure 7. Effect of temperature on: (a) rates of change of coefficient of friction (absolute value) and (b) rates of change of Raman signals at the centre and (c) edge of the track. The dashed lines are for guidance only.

occurs at low temperature, results in low $\mu_{s s}$; while high $I_{M o-s s}$ and high $\mu_{s s}$ are observed at higher temperature. The relationship between $\mu_{s s}$ and $I_{M o-s s}$ is summarised in Fig. 6 a.

The effect of temperature on friction and $\mathrm{MoS}_{2}$ formation. The effect of test temperature on the rates of change of the friction coefficient and various Raman signal intensities are shown in Fig. 7 (for definitions of various rates, see Fig. 2 in 'Data analysis' section). The rate of initial decrease in friction coefficients $\left(r_{\mu-i}\right.$, open circles, Fig. 7a) appears to follow an exponential increase with temperature. For friction curves which exhibit type B behaviour, friction coefficient increases after it reaches a minimum. The rate of increase in friction coefficient ( $r_{r e}$, open triangles) and the rate of its subsequent drop $\left(r_{\mu-2}\right.$, solid circles) are estimated (Fig. 7a). Both $r_{r e}$ and $r_{\mu-2}$ are relatively insensitive to test temperature. Note that $r_{\mu-2}$ (solid circles) is about an order of magnitude lower than $r_{\mu-i}$ (open circles, Fig. 7a).

At low temperature $\left(\leq 90^{\circ} \mathrm{C}\right)$, the rate of increase of $\mathrm{MoS}_{2}$ intensity $\left(r_{M o-i}\right)$ is low and is temperature-insensitive $\left(r_{\mathrm{Mo}-i}\right.$, open circles, Fig. $\left.7 \mathrm{~b}\right)$. At higher temperatures, $r_{\mathrm{Mo}-i}$ is not estimated since the period of initial low $I_{\mathrm{Mos}_{2}}$ is short (see $I_{\mathrm{Mos}_{2}}$ vs. time in Fig. 5b). This short period of low $I_{\mathrm{Mos}_{2}}$ is followed by a substantial rise in $I_{\mathrm{Mos}_{2}}$ and the rate of this delayed $\mathrm{IMos}_{2}$ rise is estimated $\left(r_{\mathrm{Mo}-2}\right.$, solid circles, Fig. $\left.7 \mathrm{~b}\right)$. In these high temperature tests, the rate of change in $I_{\mathrm{Mos}_{2}}\left(r_{\mathrm{Mo}_{2}}\right.$, filled circles, Fig. $\left.7 \mathrm{~b}\right)$, like the rate of change in friction coefficients $\left(r_{r e}\right.$, triangle; and $r_{\mu-2}$, circles) (Fig. 7a), are insensitive to test temperature. Note that the rate of increase in $I_{\mathrm{Mos}_{2}}$ from high temperature tests $\left(r_{\mathrm{Mo}-2}\right.$, filled circles) is higher than that from lower temperature tests $\left(r_{\mathrm{Mo}-i}\right.$, open circles), see a step change in Fig. $7 \mathrm{~b}$. These results confirm a critical temperature around $90{ }^{\circ} \mathrm{C}$ exists.

Since strong intensities from carbon D- and G-bands are observed in high temperature tests, the rates of growth of $I_{G}\left(r_{G-u p}\right)$ and its rate of subsequent decrease $\left(r_{G-\text { down }}\right)$ are also presented (open and solid squares respectively in Fig. 7b). $r_{G-u p}$ and $r_{G-\text { down }}$ drop with increasing temperature (open and solid squares respectively, Fig. 7b). It should be noted that tribofilms formed in neat $\mathrm{PAO}$ at $110^{\circ} \mathrm{C}$ give a very low $I_{D}$ and $I_{G}$ compared to those from MoDTC-containing PAO in the same test condition (Fig. S5-1 in SI 5).

The effect of shear on $\mathrm{MoS}_{2}$ formation. Experiments were conducted at $110^{\circ} \mathrm{C}$ at applied loads ranging from 30 to $70 \mathrm{~N}$. At $30 \mathrm{~N}$, type A behaviour is observed and hence only the steady state friction coefficient is defined. This highlights that both temperature and applied load contribute to the transition from type A to type B behaviour. The minimum $\mu_{\text {min }}$, maximum $\mu_{\text {max }}$, and steady state $\mu_{s s}$ friction coefficients all increase with increasing load (see Fig. 8a). This effect is the most obvious for $\mu_{\max }$. Interestingly, the effect of applied load on the rate of change of friction coefficient is weak (Fig. 8b).

Increasing the applied load promotes the growth of $\mathrm{MoS}_{2}$ and carbon, as shown by rising rates of increase of $I_{M^{\prime} s_{2}}\left(r_{M o-2}\right.$, triangles $)$ and of $I_{G}\left(r_{G-u p}\right.$, circles $)$ in Fig. 8c. The rise in these growth rates results in higher Raman intensities of $\mathrm{MoS}_{2}$ and D- and G- bands (Fig. 8d, see also Fig. 9a) and higher friction coefficient when the steady state is reached (Fig. 9b). Note that at a fixed load, $I_{M o-s s}, I_{G-s s}$ and $I_{D-s s}$ are comparable (Fig. 8d). This is also seen in tests conducted at lower temperatures (Fig. 6c).

The accumulation of $\mathrm{MoS}_{2}$ outside of contact tracks. Raman spectra obtained at the sides of the contact tracks show that $I_{\mathrm{MoS}_{2}}$ (triangles, Fig. 10) starts to increase rapidly shortly before steady state friction has been reached. At low test temperatures (Fig. 10a), $I_{M o S_{2}}$ (triangles) is higher than $I_{G}$ (squares) and $I_{D}$ (circles) throughout the test. At the end of the test (see Fig. $6 \mathrm{~d}$ ), the intensity from $\mathrm{MoS}_{2}$ peak (triangles) is higher than those of G- (squares) and D- (circles) bands of amorphous carbon although the difference decreases as temperature rises. In addition, the intensities of $\mathrm{MoS}_{2}$ peak obtained at the side of the contact track ( $I_{M o-e}$, triangles, Fig. 6d) is higher than that collected within the contact track ( $I_{M o-s s}$, triangles, in Fig. 6c).

At high test temperatures (Fig. 9b), $I_{\mathrm{MoS}_{2}}$ (triangles) is comparable to $I_{G}$ (squares) and $I_{D}$ (circles) during rubbing. $I_{M o-s s}$ (triangles), $I_{G-s s}$ (squares) and $I_{D-s s}$ (circles) within the contact track (Fig. $6 \mathrm{c}$ ) and those at the side of the track $\left(I_{M o-e}\right.$, triangles; $I_{G-e}$, squares; and $I_{D-e}$, circles respectively in Fig. $\left.6 \mathrm{~d}\right)$ are similar. This is very different from what is observed in lower temperature tests where the accumulations produced contain a much higher fraction of $\mathrm{MoS}_{2}$. 

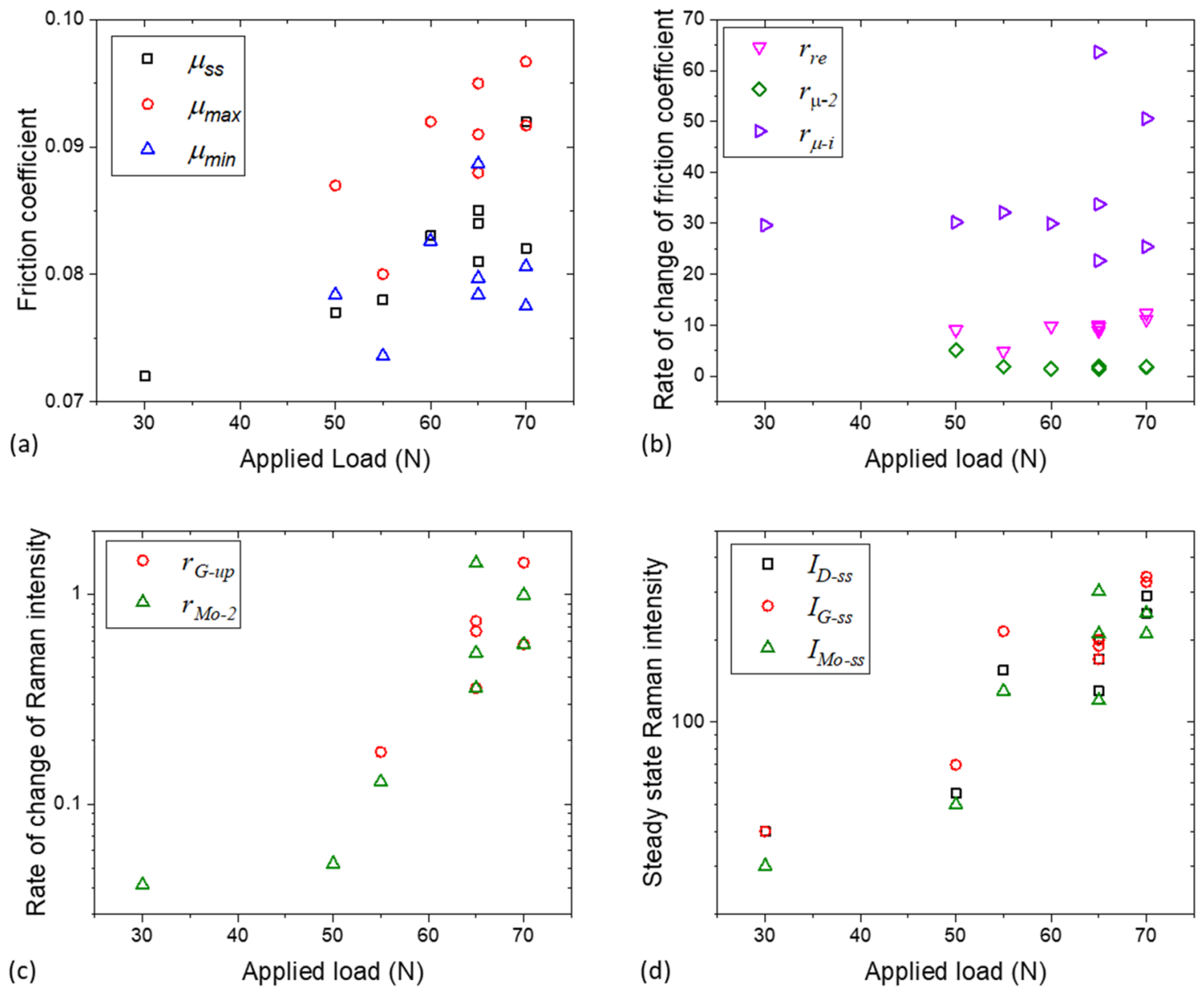

Figure 8. The effect of applied load on (a) friction coefficient; (b) rate of change of friction coefficient; (c) rate of change of intensity of $\mathrm{MoS}_{2}$ and carbon G-band Raman peaks; and (d) intensity of $\mathrm{MoS}_{2}$ and carbon G-band Raman during the steady state. Test temperature $=110^{\circ} \mathrm{C}$.
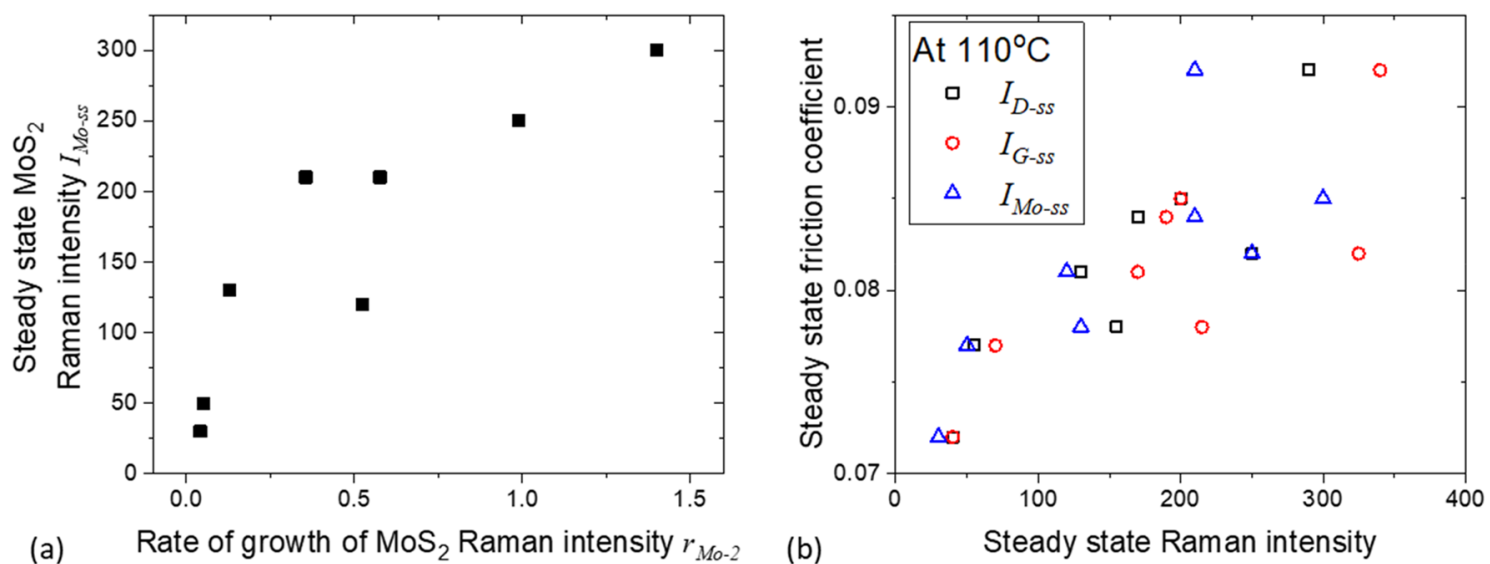

(a) Rate of growth of $\mathrm{MoS}_{2}$ Raman intensity $r_{M o-2}$

Figure 9. The effect of rate of increase of $\mathrm{MoS}_{2}$ peak intensity on (a) steady state $\mathrm{MoS}_{2}$ intensity and (b) steady state friction coefficient. Test temperature $=110^{\circ} \mathrm{C}$, applied load $=30-70 \mathrm{~N}$.

Focusing on the growth rate of carbon and $\mathrm{MoS}_{2}$, the rate of increase in $\mathrm{MoS}_{2}$ signals $\left(r_{M o-e}\right.$, circles in Fig. 7c) is slightly higher than that from amorphous carbon $\left(r_{G-e}\right.$, squares in Fig. $\left.7 \mathrm{c}\right)$ except at $110^{\circ} \mathrm{C}$ and they remain relatively constant with test temperatures. Comparing the growth rate of $\mathrm{MoS}_{2}$ in and at the edge of the contact track, the former $\left(r_{\mathrm{Mo}-i}\right.$, Fig. $\left.7 \mathrm{~b}\right)$ is slightly slower than the latter $\left(r_{\mathrm{Mo}-e}\right.$, Fig. $\left.7 \mathrm{c}\right)$ for tests done $\leq 90^{\circ} \mathrm{C}$, while $r_{\mathrm{Mo}-\mathrm{e}}$ is lower than $r_{\mathrm{Mo}-i}$ for tests done $>90^{\circ} \mathrm{C}$. 

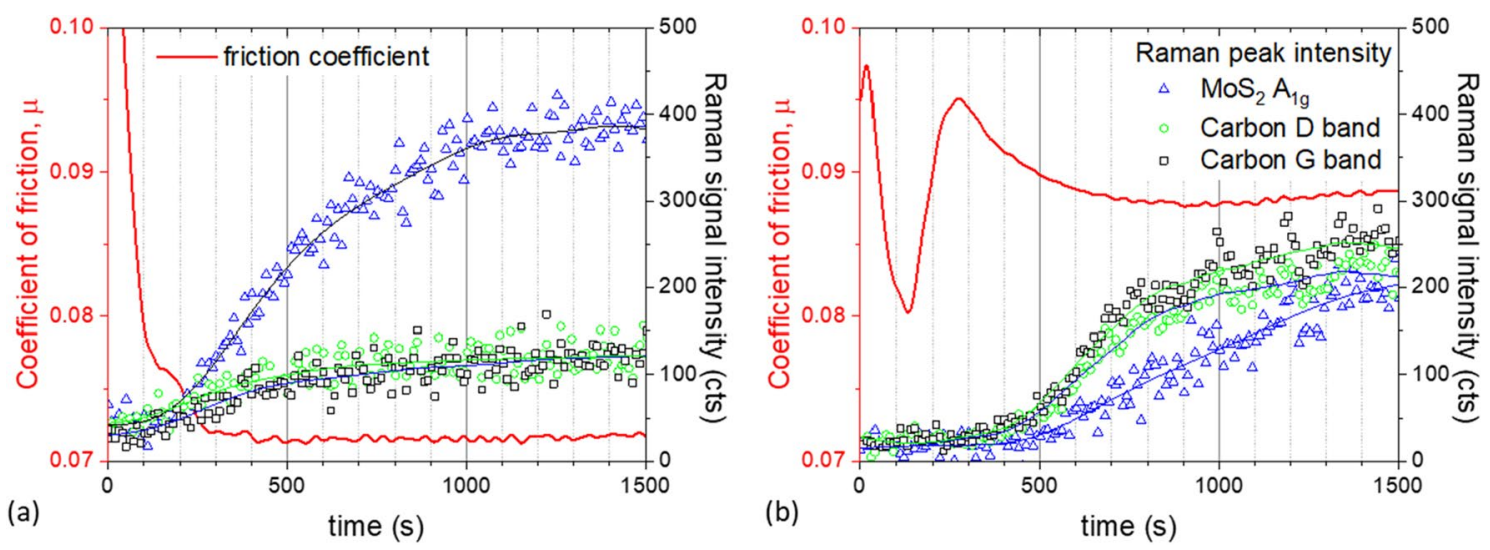

Figure 10. Friction curve and Raman signals measured at the side of the wear track at (a) $70{ }^{\circ} \mathrm{C}$; and (b) $110{ }^{\circ} \mathrm{C}$.

\section{Discussion}

At a fixed test condition, an increase in $\mathrm{MoS}_{2}$ Raman signal intensity over time may indicate either an increase in film thickness or an increase in $\mathrm{MoS}_{2}$ surface coverage. In our low-temperature experiments $\left(\leq 90{ }^{\circ} \mathrm{C}\right)$, a small initial increase in $I_{\mathrm{Mos}_{2}}$ gives a substantial reduction in friction whilst further increases in $I_{\mathrm{Mos}_{2}}$ do not correlate with any further friction reduction, suggesting that surface coverage increases. This is because friction is determined by the shear strength between $\mathrm{MoS}_{2}$ layers. It is likely that $\mathrm{MoS}_{2}$ forms at the contacting asperities ${ }^{20}$, where its friction reduction action is most efficient, and later redistributes across the contact. It is then removed from the contact track towards its edge, giving rise to the observed constant $I_{M o-s s}$. Note that the link between a reduction of friction and surface coverage of $\mathrm{MoS}_{2}$ has been reported in the literature ${ }^{11,21}$.

The observations of higher friction coefficients with increased $I_{\mathrm{Mos}_{2}}$ at high temperatures are surprising. The shape of friction curves observed at 100 and $110^{\circ} \mathrm{C}$ (Fig. 5b) has been observed by other authors ${ }^{22}$ but its origin is unclear. Note that the observed increase in $\mathrm{MoS}_{2}$ Raman signal at higher temperature as compared to low temperature film, is due to higher $\mathrm{MoS}_{2}$ content, as well as the formation of thicker film. EDX shows our high temperature tribofilm consists of patches $(\sim 100 \mathrm{~nm}$ thick) of higher carbon content formed above a thin layer with lower carbon content (Fig. 4). In the early stages of film formation, which is likely related to the formation of the bottom low $\mathrm{C}$ content layer, friction coefficient is low. Time-resolved Raman spectroscopy reveals that carbon forms rapidly and simultaneously to the observed rebound of the friction coefficient. This is likely related to the thicker, high $\mathrm{C}$ content patches formed on top of the lower $\mathrm{C}$ content layer. $\mathrm{MoS}_{2}$ forms more slowly, but when a steady-state $\mathrm{MoS}_{2}$ amount is reached, its presence appears to have the effect of slowing down carbon formation, making the carbon signal also settle at a lower, steady-state level. Our results show that the rebound of the coefficient of friction from its local minimum is attributed to the substantial rise in the amount of carbon in the tribofilm which overwhelms the effect of $\mathrm{MoS}_{2}$ formed during the period where friction sees a sharp initial fall. Note that the increased carbon content at high temperature may also lead to carbon impurities being incorporated into the $\mathrm{MoS}_{2}$ lattice. These impurities, in turn, could impair the friction anisotropy effect, rendering the tribofilm less effective at reducing friction ${ }^{5}$.

Note that olefins are known to dehydrogenate and break up to form a graphitic tribofilm when the surfaces are covered with a catalytic coating (for example $\left.\mathrm{MoN}_{\mathrm{x}}-\mathrm{Cu}\right)^{23}$. Recently this phenomenon has also been reported on uncoated surfaces ${ }^{24}$. The carbonaceous materials observed in the high temperature tribofilm here may come from the degradation of the base oil PAO. The lack of a more catalytic substrate in our case may explain why high carbon Raman signal is only observed in high temperature tests.

Tests with neat PAO (without MoDTC additive) result in high friction and substantial surface damage. An analysis of the tribofilm generated from neat PAO confirmed that amorphous carbon in the patchy layers formed in MoDTC-doped PAO is likely to be originated from PAO (see SI 5). Tribofilms formed in neat PAO at $110^{\circ} \mathrm{C}$ give a very low $I_{D}$ and $I_{G}$ compared to those from MoDTC containing PAO in the same test condition. These results indicate that firstly, a carbon-rich tribofilm, such as one formed in neat PAO, offers minimum, if any, surface protection in our case and leads to high friction. Secondly, the combination of MoDTC or MoS ${ }_{2}$, with high test temperatures and shear, promotes the formation of carbonaceous materials on rubbing surfaces. This suggests MoDTC, $\mathrm{MoS}_{2}$ or their intermediate species promotes the degradation of PAO in our test conditions. Thirdly, the increase in the amount of $\mathrm{MoS}_{2}$ in the high temperature tribofilm is not sufficient to reduce friction to the level achieved at low temperature.

Taking results from Figs. 8 and 9 together, a high applied load at high temperature promotes the formation of a tribofilm. This is shown by an increase in the rate of formation of $\mathrm{MoS}_{2}$ and carbon. While the tribofilm contains a high levels of $\mathrm{MoS}_{2}$ and carbon at the steady state, our results suggest that the observed higher friction coefficient is linked to the higher carbon content. It is possible that, as the amount of carbonaceous materials in the tribofilm increases, the rise in friction coefficient, and hence the shear stress, encourages further production of both carbonaceous materials and $\mathrm{MoS}_{2}$. As the amount of $\mathrm{MoS}_{2}$ in the tribofilm rises however, the friction coefficient drops due to its lower shear strength, which in turn hampers the growth of carbonaceous materials. A steady state is eventually reached on the composition of the tribofilm and the friction coefficient (see Fig. 5b).

The chemistry of the accumulations at the edge of the contact track provides insights into the nature of the tribofilm in the contact track during rubbing. At low test temperatures, these accumulations consist mainly of 


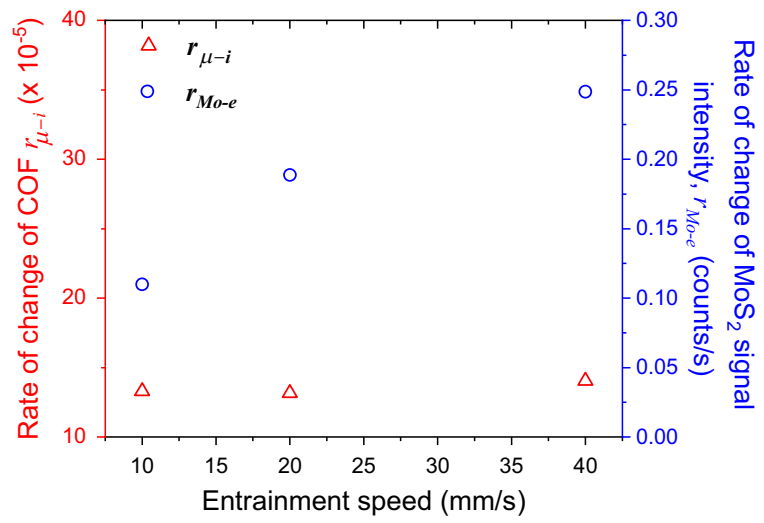

Figure 11. The accumulation rate outside the contact track increases linearly with speed (number of passes), while the rate of change of friction coefficient remains constant. Test conducted at $80^{\circ} \mathrm{C}$, applied load $=70 \mathrm{~N}$ and $\mathrm{SRR}=150 \%$.

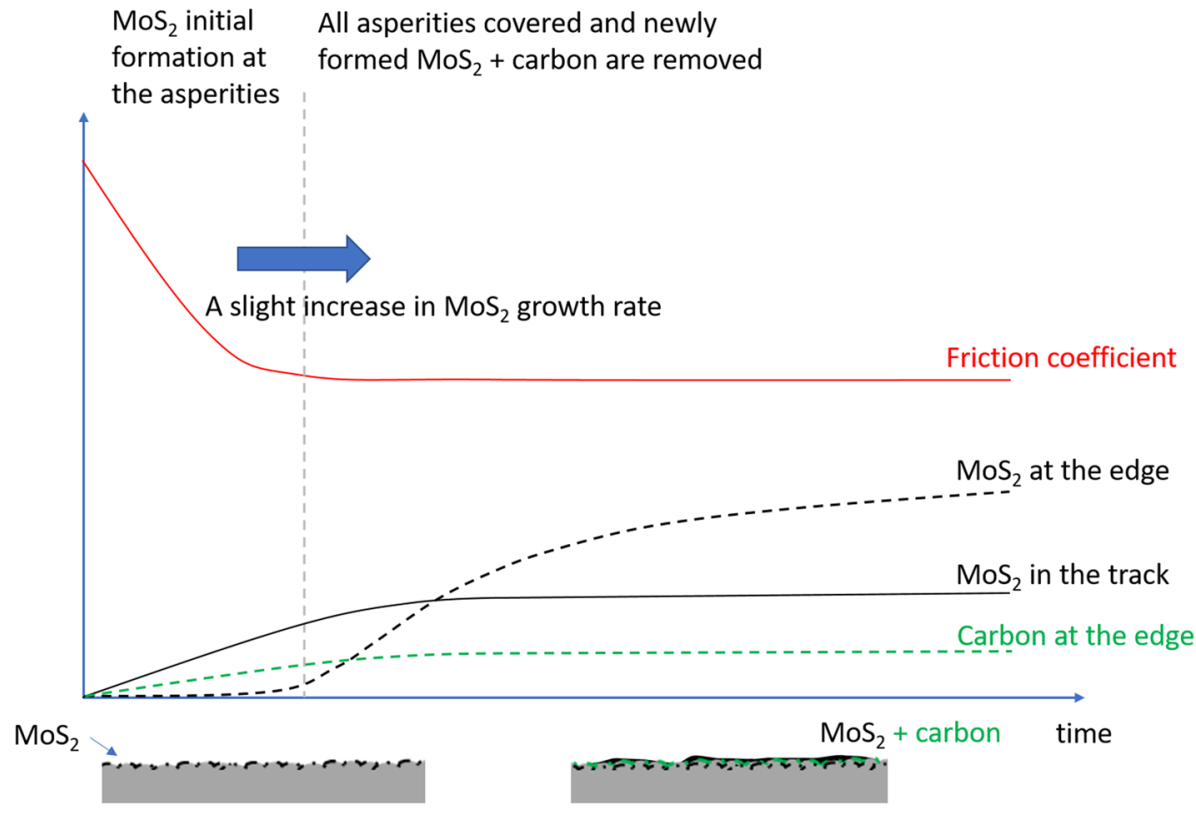

Figure 12. Schematic representation of the variation in friction and Raman signal over time during a low temperature $\left(<90^{\circ} \mathrm{C}\right.$ test $)$.

$\mathrm{MoS}_{2}$, its amount increasing with time (Fig. 10a). Some carbon is also found. Both the amount of carbon and $\mathrm{MoS}_{2}$ at the edge are higher than those detected in the contact track (Fig. 6 and 6d). Note that the difference between $I_{M o-e}$ and $I_{M o-s s}$ is larger than those between $I_{D-e}$ and $I_{D-s s}$, and between $I_{G-e}$ and $I_{G-s s}$. This suggests that while the initial tribofilm contains carbonaceous materials, the tribofilm formed subsequently is mainly composed of $\mathrm{MoS}_{2}$. This low shear strength $\mathrm{MoS}_{2}$ is then being pushed away constantly during rubbing and accumulated just outside the track. As a result, the amount of tribofilm on the contact track is always low.

At high test temperatures, accumulations at the edge of contact tracks contain $\mathrm{MoS}_{2}$, as well as carbonaceous materials (Fig. 10b), and their amount at steady state are similar to those in the contact track (Fig. 6c vs 6d). This suggests that both carbon and $\mathrm{MoS}_{2}$ are continuously formed in the contact and are removed together during rubbing. Friction results show that this mixed tribofilm is not as effective in reducing friction as the $\mathrm{MoS}_{2}$ tribofilm.

The rate of $\mathrm{MoS}_{2}$ accumulation at the edge of the rubbing track $\left(r_{M o-e}\right)$ is temperature independent. Tests conducted at different entrainment speeds show that the rate of $\mathrm{MoS}_{2}$ accumulation at the edge of the rubbing track (circles, Fig. 11) increases roughly linearly with entrainment speed, while the rate of change of friction coefficient $r_{\mu-i}$ remains constant (triangles, Fig. 11). This suggests that the amount accumulated is governed by the number of contact passes. Our results support that the accumulation process is likely to be mechanically-, rather than chemically-, driven, i.e. $\mathrm{MoS}_{2}$ formed in the contact track is pushed to the edge of the track during rubbing (the cross section observed in Fig. 3). Note that the accumulation of $\mathrm{MoS}_{2}$ does not affect the rate of friction reduction or the steady state friction coefficient. 


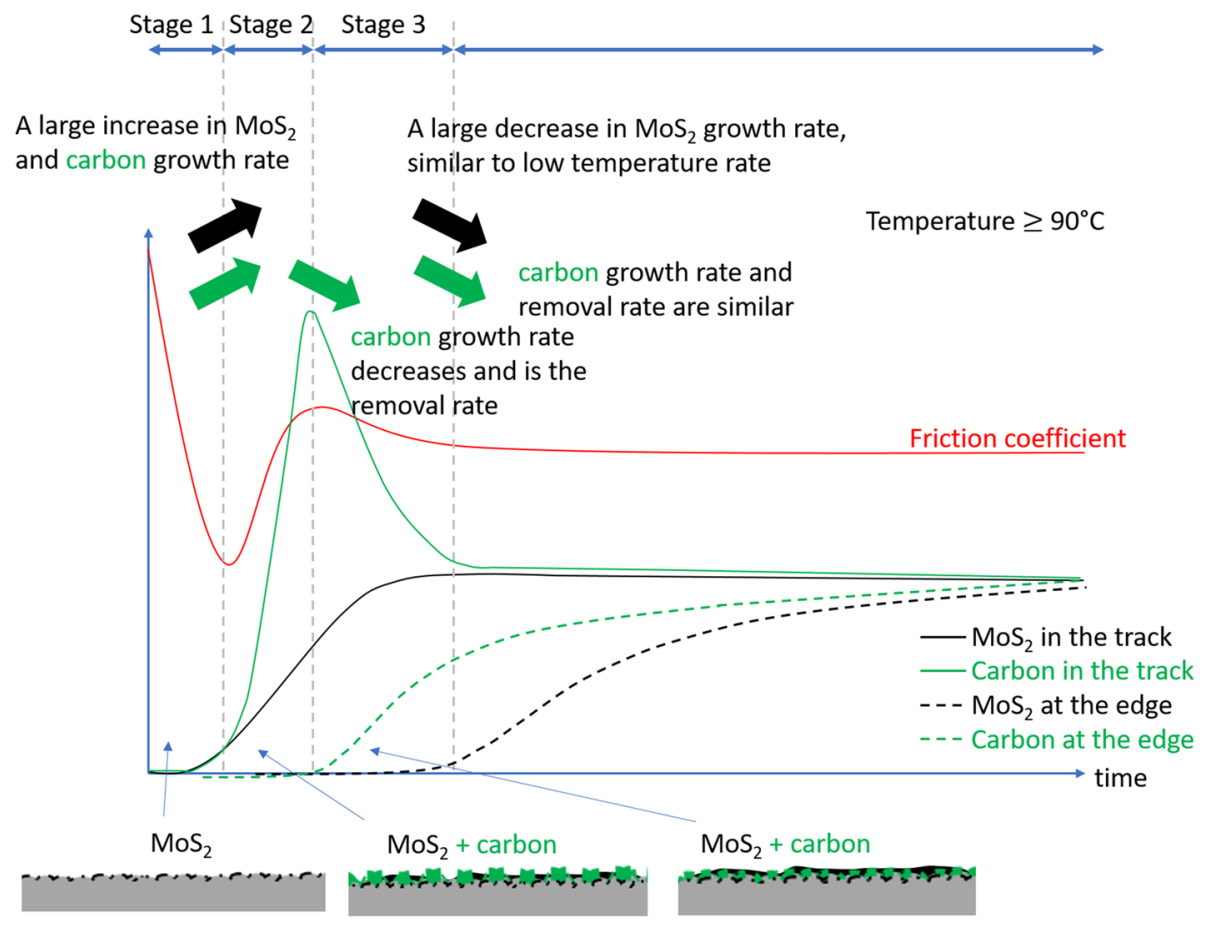

Figure 13. Schematic representation of the variation in friction and Raman signal over time during a hightemperature $\left(>90^{\circ} \mathrm{C}\right.$ test $)$.

Figs. 12 and 13 show schematic representations of the time-resolved Raman signals and friction, interpreted in the context of related literature (shear-induced decomposition of MoDTC is more favourable for the formation of $\mathrm{MoS}_{2}$ at asperities, which then gets redistributed around the surface by mechanical processes) ${ }^{14,17,25,26}$. Some features are exaggerated for clarity. At test temperatures $\leq 90{ }^{\circ} \mathrm{C}$ (Fig. 12), the rate of decrease of friction coefficient $\left(r_{\mu-i}\right)$ is related to a tribofilm with a small amount of carbon and $\mathrm{MoS}_{2}$. Despite its low rate, the growth of $\mathrm{MoS}_{2}$ soon overtakes that of carbon. As a result, the accumulation at the edge of the track is $\mathrm{MoS}_{2}$-rich. Taken into consideration of tribofilm removal during rubbing, our results suggest the actual growth rates of $\mathrm{MoS}_{2}$ initially and during the transition to a stable low friction coefficient are at least equal to the rate of growth of $\mathrm{MoS}_{2}$ signals obtained in the track $\left(r_{M o-i}\right)$ and at the edge of the track $\left(r_{M o-e}\right)$ respectively. The small amount of $\mathrm{MoS}_{2}$ remained on the contact track is sufficient to provide a low and stable steady state coefficient of friction. This is due to the build-up of $\mathrm{MoS}_{2}$ on the contact track ${ }^{10}$, especially at asperities ${ }^{20}$.

At test temperature $\geq 90^{\circ} \mathrm{C}$ (Fig. 13), the growth of $\mathrm{MoS}_{2}$ can be divided into three stages. The initial stage (stage 1) is like that observed $\leq 90^{\circ} \mathrm{C}$. Although $r_{M o-i}$ values are not estimated in these cases, it is probable that they are similar to those at lower temperature. This is supported by (1) the temperature insensitivity of $r_{M o-i}$ at lower temperature, and (2) the rate of initial drop in friction $\left(r_{\mu-1}\right)$ across both temperature ranges can be described by the same exponential relationship. This suggests that the nature of the tribofilms and the friction reduction mechanisms at this stage of the friction curve are likely to be similar across the whole test temperature range.

Stage 2 starts when the friction coefficient is at its minimum. Both the amount of carbon and $\mathrm{MoS}_{2}$ increase rapidly. Note that the rate of increase of carbon signals $\left(r_{G-u p}\right)$ is higher than from $\mathrm{MoS}_{2}\left(r_{M o-2}\right)$. Stage 2 ends when friction coefficient reaches a local maximum. At Stage 3, the amount of carbon drops at a rate of $r_{G-\text { down }}$ while friction coefficient reduces gradually at a rate $r_{\mu-2}$. The steady state tribofilm in these cases have more carbon and $\mathrm{MoS}_{2}$ than their lower temperature counterpart.

Focusing on the growth of $\mathrm{MoS}_{2}$, our results suggest the growth rates of $\mathrm{MoS}_{2}$ at stage 1, 2 and 3 are at least $r_{M o-i}, r_{M o-2}$ and $r_{M o-e}$ respectively. The growth rate of carbon at stage 2 would be at least, $r_{G-u p}$ while at stage 3 , its maximum rate is $r_{G-e}$.

The origin of Stage 2, where the amount of carbon and $\mathrm{MoS}_{2}$ rise with friction coefficient, is unclear. Our results show that the formation of carbon is favoured at higher temperature and is likely due to the degradation of the base oil PAO. This suggests that the PAO degradation process has a relatively high energy barrier. Such barrier may be overcome during rubbing by an increase of temperature due to frictional heating and mechanical energy in the form of shear. This may explain the load dependence on the growth of $I_{D}$ and $I_{G}$. As the carbon tribofilm in this case is ineffective in friction reduction, the increased friction may promote further the growth of carbonaceous materials as a test progresses. Note that a similar shear dependence also applies to the growth of $\mathrm{MoS}_{2}$. As the amount of $\mathrm{MoS}_{2}$ in the tribofilm rises, friction eventually drops and the conditions become less favourable for the formation of carbon, resulting in a reduction of $I_{D}$ and $I_{G}$. Eventually, the amount of carbon and $\mathrm{MoS}_{2}$ stabilise, together with the coefficient of friction. 


\section{Conclusions}

MoDTC is one of the most effective friction reduction additives. It is known to form a $\mathrm{MoS}_{2}$ tribofilm on steel surfaces under shear conditions. The detailed formation mechanism of this tribofilm, however, remains elusive. In this study, a new experimental platform combining Raman spectroscopy and a sphere-on-disc tribometer is set up. It allows us to monitor in real time the formation of $\mathrm{MoS}_{2}$ tribofilms on steel surfaces lubricated with MoDTC-containing PAO.

As the formation of this tribofilm is a tribochemical process, both temperature and shear stress are important factors. We have shown that the nature of the tribofilm is temperature dependent. A critical temperature of $90^{\circ} \mathrm{C}$ is identified for our test conditions. Below $90^{\circ} \mathrm{C}$, the tribofilm is mainly $\mathrm{MoS}_{2}$, that provides a low friction coefficient. This tribofilm is constantly being formed and then removed mechanically during rubbing. The balance between the formation and removal process results in only a small amount of $\mathrm{MoS}_{2}$ at any time covering the track when steady state is achieved. Above the critical temperature, the tribofilm consists of patches $(\sim 100 \mathrm{~nm}$ thick $)$ of higher carbon and $\mathrm{MoS}_{2}$ content formed above a thin layer with carbon and $\mathrm{MoS}_{2}$ content similar to those of the low temperature tribofilm. The high temperature tribofilm is again continuously being formed and removed during rubbing. It gives higher friction than its low temperature counterpart despite having a large amount of $\mathrm{MoS}_{2}$. The proportion of $\mathrm{MoS}_{2}$ and amorphous carbon in the high temperature tribofilm changes throughout the test, and a positive correlation is found between carbon Raman signal intensity and friction coefficient. Our results suggest that carbonaceous material in the tribofilm originates from PAO degradation. This mixed tribofilm starts off richer in carbon and this is accompanied by a sharp rise in friction. Only when the amount of $\mathrm{MoS}_{2}$ is sufficiently high does the friction coefficient drop and plateau at an intermediate level.

Apart from temperature, increasing applied load increases the growth rate and the steady state amount of $\mathrm{MoS}_{2}$. This highlights the role of mechanical energy in promoting chemical reactions in a rubbing contact and underscores the formation of this tribofilm is an mechanochemical process.

This work shows that while MoDTC can reduce friction in a wide range of temperatures, its effectiveness is temperature and load dependent due to a change of the nature of the tribofilm. Since carbon in tribofilms formed at higher temperature is attributed to the degradation of PAO, this shows that the choice of the base fluid and its potential reactions can be consequential to the effectiveness of additives and the frequency of lubricant change in engineering applications.

Received: 4 August 2020; Accepted: 1 January 2021

Published online: 11 February 2021

\section{References}

1. Holmberg, K. \& Erdemir, A. Influence of tribology on global energy consumption, costs and emissions. Friction 5, 263-284. https ://doi.org/10.1007/s40544-017-0183-5 (2017)

2. Galvão, C., Tomanik, E., Fujita, H., Paes, E. \& Morais, P. (2017) Advantages and challenges for low viscosity oils in emergent countries. 1. https://doi.org/10.4271/2017-36-0387 (2017).

3. Macian, V., Tormos, B., Miró, G. \& Pérez, T. Assessment of low-viscosity oil performance and degradation in a heavy duty engine real-world fleet test. Proc. Inst. Mech. Eng. Part J: J. Eng. Tribol. 230, 729-743. https://doi.org/10.1177/1350650115619612 (2015).

4. Espejo, C. et al. MoDTC tribochemistry in steel/steel and steel/diamond-like-carbon systems lubricated with model lubricants and fully formulated engine oils. J. Tribol. 141, 012301. https://doi.org/10.1115/1.4041017 (2018).

5. Martin, J. M., Donnet, C., Le Mogne, T. \& Epicier, T. Superlubricity of molybdenum disulphide. Phys, Rev. B Condens. Matter. 48, 10583-10586. https://doi.org/10.1103/physrevb.48.10583 (1993).

6. Li, M. et al. Experimental study and modeling of atomic-scale friction in zigzag and armchair lattice orientations of MoS2. Sci. Technol. Adv. Mater. 17, 189-199. https://doi.org/10.1080/14686996.2016.1165584 (2016).

7. Martin, J. M. et al. Superlubricity of Mos2-crystal orientation mechanisms. Surf. Coat. Technol. 68, 427-432. https://doi. org/10.1016/0257-8972(94)90197-X (1994).

8. Onodera, T. et al. A computational chemistry study on friction of h-MoS(2). Part II. Friction anisotropy. J. Phys. Chem. B 114, 15832-15838. https://doi.org/10.1021/jp1064775 (2010).

9. Topolovec Miklozic, K., Graham, J. \& Spikes, H. Chemical and physical analysis of reaction films formed by molybdenum dialkyl-dithiocarbamate friction modifier additive using raman and atomic force microscopy. Tribol. Lett. 11, 71-81. https://doi. org/10.1023/a:1016655316322 (2001).

10. Graham, J., Spikes, H. \& Korcek, S. The friction reducing properties of molybdenum dialkyldithiocarbamate additives: part I-factors influencing friction reduction. Tribol. Trans. 44, 626-636. https://doi.org/10.1080/10402000108982504 (2001).

11. Xu, D. et al. Understanding the friction reduction mechanism based on molybdenum disulfide tribofilm formation and removal. Langmuir 34, 13523-13533. https://doi.org/10.1021/acs.langmuir.8b02329 (2018).

12. Grossiord, C. et al. MoS2, single sheet lubrication by molybdenum dithiocarbamate. Tribol. Int. 31, 737-743. https://doi. org/10.1016/S0301-679x(98)00094-2 (1998).

13. De Barros Bouchet, M. I. et al. Mechanisms of MoS2 formation by MoDTC in presence of ZnDTP: effect of oxidative degradation. Wear 258, 1643-1650. https://doi.org/10.1016/j.wear.2004.11.019 (2005).

14. Khaemba, D. N., Neville, A. \& Morina, A. New insights on the decomposition mechanism of molybdenum dialkyldithiocarbamate (MoDTC): a Raman spectroscopic study. RSC Adv. 6, 38637-38646. https://doi.org/10.1039/c6ra00652c (2016).

15. Kurihara, K. \& Phan, Q. T. N. In International tribology conference.

16. Rai, Y., Neville, A. \& Morina, A. Transient processes of MoS2 tribofilm formation under boundary lubrication. Lubr. Sci. 28, 449-471. https://doi.org/10.1002/ls.1342 (2016).

17. Okubo, H., Yonehara, M. \& Sasaki, S. In Situ Raman observations of the formation of MoDTC-derived tribofilms at steel/steel contact under boundary lubrication. Tribol. Trans. 10, 1-8. https://doi.org/10.1080/10402004.2018.1462421 (2018).

18. Hoffman, E. E. \& Marks, L. D. Graphitic carbon films across systems. Tribol. Lett. https://doi.org/10.1007/s11249-016-0720-9 (2016).

19. Hamrock, B. J. \& Dowson, D. Isothermal elastohydrodynamic lubrication of point contacts: part 1-theoretical formulation. J. Lubr. Technol. 98, 223-228. https://doi.org/10.1115/1.3452801 (1976).

20. Greene, A. B. \& Risdon, T. J. The effect of molybdenum-containing, oil-soluble friction modifiers on engine fuel economy and gear oil Efficiency. SAE Tech. Pap. 10, 811187. https://doi.org/10.4271/811187 (1981). 
21. Vaitkunaite, G. et al. MoS2 tribofilm distribution from low viscosity lubricants and its effect on friction. Tribol. Int. 151, 106531. https://doi.org/10.1016/j.triboint.2020.106531 (2020).

22. Yamamoto, Y. \& Gondo, S. Friction and wear characteristics of molybdenum dithiocarbamate and molybdenum dithiophosphate. Tribol. Trans. 32, 251-257. https://doi.org/10.1080/10402008908981886 (1989).

23. Erdemir, A. et al. Carbon-based tribofilms from lubricating oils. Nature 536, 67-71. https://doi.org/10.1038/nature18948 (2016).

24. Wu, H. et al. Formation and nature of carbon-containing tribofilms. ACS Appl. Mater. Interfaces 11, 16139-16146. https://doi. org/10.1021/acsami.8b22496 (2019).

25. Khaemba, D. N., Jarnias, F., Thiebaut, B., Neville, A. \& Morina, A. The role of surface roughness and slide-roll ratio on the decomposition of MoDTC in tribological contacts. J. Phys. D Appl. Phys. 50, 085302. https://doi.org/10.1088/1361-6463/aa5905 (2017).

26. Zhang, J. \& Spikes, H. On the mechanism of ZDDP antiwear film formation. Tribol. Lett. 63, 10-15. https://doi.org/10.1007/s1124 9-016-0706-7 (2016).

\section{Acknowledgements}

This work is supported by Engineering and Physical Science Research Council EPSRC project EP/P030211/1. The authors acknowledge Taiho Kogyo Tribology Research Foundation for its financial support of equipment. The authors would like to thank Shell Lubricants Japan K.K. for kindly supplying the base oils and additives for this study. The authors would also like to thank Dr Jie (Jason) Zhang for his help in friction testing and Prof Luca di Mare for very helpful discussions.

\section{Competing interests}

The authors declare no competing interests.

\section{Additional information}

Supplementary Information The online version contains supplementary material available at https://doi. org/10.1038/s41598-021-81326-0.

Correspondence and requests for materials should be addressed to J.S.S.W.

Reprints and permissions information is available at www.nature.com/reprints.

Publisher's note Springer Nature remains neutral with regard to jurisdictional claims in published maps and institutional affiliations.

Open Access This article is licensed under a Creative Commons Attribution 4.0 International License, which permits use, sharing, adaptation, distribution and reproduction in any medium or format, as long as you give appropriate credit to the original author(s) and the source, provide a link to the Creative Commons licence, and indicate if changes were made. The images or other third party material in this article are included in the article's Creative Commons licence, unless indicated otherwise in a credit line to the material. If material is not included in the article's Creative Commons licence and your intended use is not permitted by statutory regulation or exceeds the permitted use, you will need to obtain permission directly from the copyright holder. To view a copy of this licence, visit http://creativecommons.org/licenses/by/4.0/.

(C) The Author(s) 2021 